\author{
Teresa Cristina de Novaes Marques \\ Universidade de Brasília
}

\title{
Entre o igualitarismo e a reforma dos direitos das mulheres: Bertha Lutz na Conferência Interamericana de Montevidéu, $1933^{1}$
}

\begin{abstract}
Resumo: A Conferência Interamericana, realizada no Uruguai em novembro de 1933, marca o início de uma longa e consistente cooperação de Bertha Lutz com a diplomacia brasileira. Essa conferência representou uma vitória temporária de parcela radical do feminismo norteamericano - o National Party of Women - ao qual Bertha se opunha, por convicção e fidelidade pessoal a outros grupos feministas. Este ensaio examina as razões para os meios diplomáticos aderirem a defesa dos direitos das mulheres. O debate travado em Montevidéu também ilumina a compreensão do pensamento político de Bertha Lutz e abre novas perspectivas historiográficas para as culturas políticas dos feminismos.
\end{abstract}

Palavras-chave: culturas políticas dos feminismos; Bertha Lutz; direitos iguais.

Copyright (๑) 2013 by Revista Estudos Feministas.

1 Este artigo é um produto do projeto de pesquisa "Museu Virtual Bertha Lutz", desenvolvido na UNB, com apoio do CNPq. A autora agradece a assistência dos arquivistas no Arquivo Histórico do Itamaraty (Rio de Janeiro) e no Museu Nacional e no Arquivo Histórico da Câmara dos Deputados.

${ }^{2}$ Rachel SOIHET, 2006.

\section{Apresentação}

A atuação política de Bertha Lutz em prol do voto e dos direitos das mulheres foi objeto de numerosos estudos historiográficos, a exemplo da importante contribuição de Soihet. ${ }^{2}$ Entretanto, a maior parte dos estudos enfatiza as alianças e as estratégias de Lutz, e de suas colaboradoras, no âmbito da política doméstica, ao passo que as suas iniciativas no plano da políitica externa do Brasil e das Américas não recebeu a atenção devida até o momento. Outro aspecto da vida de Lutz que deve ser examinado são os vínculos políticos e pessoais que ela mantinha com grupos feministas internacionais, sobretudo os norte-americanos e ingleses. Sustento que a aproximação calculada com o meio diplomático constituiu uma peça importante na estratégia 
traçada por Lutz para promover reformas nos direitos das mulheres no país e, ao mesmo tempo, consolidava suas alianças com grupos feministas no exterior.

Para alcançar esses objetivos, Lutz enfrentou vários obstáculos. Primeiramente, foi preciso conquistar espaço político no meio diplomático, e sua estreia em conferências oficiais compondo a delegação brasileira se deu de modo modesto, como mera conselheira técnica. A despeito disso, ela teve o cuidado de ser amparada pelo capital político familiar, contando com o apoio incondicional do Dr. Carlos Chagas, que foi nomeado delegado plenipotenciário da Conferência. A segunda dificuldade vinha das próprias feministas representadas na Conferência, pois as divergências filosóficas e políticas entre Lutz e as integrantes da delegação norte-americana afloraram no transcurso da reunião.

Ao final, Lutz colheu vitórias de sua participação na reunião no Uruguai. Ela propôs com sucesso que os países assumissem o compromisso de nomear delegadas para as conferências interamericanas dos anos seguintes, além de ter recebido expressiva cobertura da imprensa carioca. Já suas relações pessoais com a delegada dos EUA, Doris Stevens, foram seriamente abaladas pelo embate de ideias que ambas tiveram durante a reunião. Ao antagonizar Stevens, Lutz defendeu a condução política cautelosa das reformas dos direitos das mulheres nas Américas, além de frear 0 avanço das feministas do National Women's Party (NWP) na política pan-americana, gesto que certamente agradava às irmãs do League of Women Voters.

Um a um esses atores políticos surgirão na narrativa, quando for oportuno traçar seus perfis, e suas ações forem relevantes para compreender a trama políica urdida nos bastidores da conferência. Essa abordagem, creio, amplia a compreensão do próprio pensamento político de Lutz sobre a questão da igualdade plena entre homens e mulheres.

Este artigo está organizado em três seções, seguidas das considerações finais. Na primeira seção, examino o contexto da conferência de Montevidéu e o lugar dos direitos das mulheres na política pan-americana. Na segunda seção, examino o confronto político entre Lutz e as feministas norteamericanas presentes na reunião. A terceira seção é dedicada ao pensamento de Lutz sobre o igualitarismo e a promoção de reformas na condição jurídica e social da mulher e, em particular, à leitura que a feminista fazia do sistema político brasileiro ao seu tempo. As conclusões sintetizam as ideias expostas no artigo. 
${ }^{3}$ Moniz L. A. BANDEIRA, 1998.

${ }^{4}$ Em toda a documentação consultada, não se encontra a expressão América Latina para denominar os países de língua latina congregados na organização Interamericana.

${ }^{5}$ Bryce WOOD, 1961, p. 118-120.

${ }^{6}$ O Jornal, 7 jan. 1934. Anexado ao Dossiê: VII Conferência Internacional Americana, Montevideo, 1933 [962.VII, 9.279, AHI]. (ARQUIVO HISTÓRICO..., 1933b).

\footnotetext{
${ }^{7}$ Diário de Notícias, 28 dez. 1933. Anexado ao Dossiê: Congressos e Conferências Internacionais. Assuntos gerais, 1931-1951. [100, I. 2064, 37.139, AHI] (ARQUIVO HISTÓRICO..., 1931-1951).
}

\section{A Conferência de Montevidéu no pan- americanismo}

A conferência interamericana realizada em novembro de 1933, em Montevidéu, foi a primeira sob a administração democrata de Franklin Roosevelt. Naqueles dias, todos os países das Américas viviam o impacto da recessão econômica mundial, causada pelo colapso da Bolsa de Nova York. Ao desemprego, à retração do comércio de commodities e às crises bancárias experimentadas em toda parte, somavase o conflito armado no Chaco, envolvendo diretamente a Bolívia e o Paraguai, mas afetando indiretamente os interesses argentinos e norte-americanos na região. ${ }^{3}$

Havia forte expectativa a respeito do comportamento da diplomacia norte-americana diante do quadro de tensão na América Hispânica e no Brasil. ${ }^{4}$ Nas conferências anteriores, - Departamento de Estado dos EUA resistira a assumir O compromisso de não intervir militarmente em países da região, caso julgasse que os investimentos norte-americanos estivessem ameaçados. O mal-estar era agravado pela atitude dos representantes diplomáticos desse país, acusados de agir com arrogância, o que levava as autoridades latinas a nutrir pelos EUA sentimentos de antipatia e desconfiança. ${ }^{5}$ Premido por seus próprios graves problemas internos, o governo Roosevelt anunciou renunciar ao uso da força em defesa dos interesses dos Estados Unidos no Continente e, assim, evitar gastos militares em um momento econômico particularmente difícil. Esse anúncio veio acompanhado do novo estilo pessoal do Secretário de Estado, Cordel Hull, mais amistoso com seus interlocutores. Ainda assim, os países hispânicos buscaram se certificar de que os tempos eram outros e insistiram em obter da conferência um compromisso formal pela não intervenção em assuntos domésticos alheios. Durante a conferência, os trabalhos na subcomissão encarregada de elaborar a convenção dos Direitos e Deveres dos Estados exigiram muita negociação, relatou o delegado brasileiro Francisco Campos. ${ }^{6}$ Isso porque os países mais afetados pela políica externa norte-americana desejavam que o compromisso fosse redigido de modo a definir detalhadamente todas as formas de interferência. Ao final, relatou Campos, prevaleceu a redação vaga e palatável para a delegação dos EUA.

A assinatura da convenção e a trégua entre os países beligerantes foram as grandes realizações dessa conferência em Montevidéu. É certo que Cordell Hull conclamou os 21 países congregados no pan-americanismo a reduzir as barreiras tarifárias, no que todos assentiram, mas certamente não cumpriram. ${ }^{7} \mathrm{O}$ importante é que a cooperação entre os países saiu fortalecida da conferência, embalada pelas 
8 Jornal do Comércio, $28 \mathrm{dez}$ 1933. Anexado ao dossiê: Congressos e Conferências Internacionais. Assuntos gerais, 1931-1951 [100, I. 2064, 37.139, AHI] (ARQUIVO HISTÓRICO..., 19311951).

9 Com a notória exceção dos Estados Unidos, cujo Legislativo rejeitou a adesão do país à Liga das Nações, como é largamente discutido na historiografia.

${ }^{10}$ WOOD, 1961, p. $300-330$

manifestações otimistas de Hull sobre as possibilidades de diálogo: "O panamericanismo significa a paz, o sustentáculo da democracia, a conservação da independência e igualdade dos Estados e coordenação permanente dos povos em favor da paz e da liberdade."8

Não se tratava de mera retórica diplomática, pois as conferências interamericanas, por sua regularidade e abrangência, representaram um contraponto aos fóruns diplomáticos europeus, particularmente, à Liga das Nações, na qual quase todos os países americanos tinham assento, mas interferiam pouco na agenda política. ${ }^{9}$ As conferências promoviam o contato formal entre os países do Continente e funcionavam em via de mão dupla, isto é, tanto serviam para que a diplomacia norte-americana pressionasse seus parceiros e vizinhos em favor dos seus interesses como para que estes expressassem seus pontos de vista. ${ }^{10}$

Por essas ações, a política externa conduzida pelos democratas dava sinais de ruptura com o estilo adotado pelas administrações republicanas anteriores no que diz respeito à condução da defesa de investimentos dos EUA no exterior e de temas militares. ${ }^{11}$ Havia, no entanto, um assunto na agenda de discussão da conferência que apresentava uma clara continuidade com a política instituída nos fóruns interamericanos dos anos 1920: a reforma dos direitos das mulheres nas Américas.

A defesa dos direitos das mulheres no Continente compunha uma parcela da diplomacia cultural norte-americana desenvolvida nos anos 1920 , com boa resposta dos meios diplomáticos e da opinião pública. Apoiadas pelos republicanos, ainda que relutantes em admiti-lo, as feministas do National Women's Party (NWP) alcançaram grande sucesso na conferência de Havana, em 1928, quando propuseram e aprovaram a criação da Comissão Interamericana de Mulheres. Doris Stevens foi alçada à presidência da entidade, que foi instalada, com caráter de agência oficial de estudos da condição feminina, em Washington. Isso porque, nos seus inícios, os estatutos da Comissão previam para a entidade apenas $O$ caráter de agência consultiva. ${ }^{12}$

A emergência da Comissão guarda relações com a política externa dos governos Republicanos, especialmente pela ênfase no igualitarismo, tese defendida no partido nos anos 1930 e ainda durante a Guerra. ${ }^{13}$ Entretanto, os atores políticos que se aliavam para levar à cena externa a tese do igualitarismo iam além das feministas do NWP e do Departamento de Estado, uma vez que grupos empresariais privados também agiam como braço da diplomacia norteamericana. Em particular, a fundação Carnegie Endowment for Peace colaborava estreitamente com as feministas do NWP. 
${ }^{14}$ Wanderson Chaves examina a estreita colaboração de grupos empresariais, na forma de fundações privadas, com a política externa norte-americana no pósguerra, sob o contexło da Guerra Fria. CHAVES, 2011. Antes disso, há indícios de intervenções individuais na política externa norteamericana, a exemplo de uma conferência pacifista patrocinada por Henry Ford, com a participação de feministas ligadas a Carrie Catt, em dezembro de 1915. Ver: Christine BOLT, 2004.

${ }^{15} \mathrm{O}$ ofício, datado de 7 de julho de 1931, assinado por James Brown Scott, identificado como diretor da Seção de Direito Internacional da Carnegie Endowment, em nome do Conselho Executivo do Instituto Americano de Direito Internacional e a pedido da Comissão Interamericana de Mulheres. Anexado ao Dossi: "Direitos da Mulher, 1931-1939. [502.63, 1.237 , m. 27.551; AHI]. (ARQUIVO HISTÓRICO ..., 1933a).

${ }^{16}$ Ofício do Ministro de Estado da Justiça e Negócios Interiores, Oswaldo Aranha, ao Ministro das Relações Exteriores, em 5 out. 1931. Anexado ao Dossi: "Direitos da Mulher, 1931-1939. [502.63, 1.237 , m. 27.551; AHI]. (ARQUIVO HISTORICO..., 1933a).

${ }_{17}$ Carta convite para trabalha para o Instituto Americano de Direito Internacional. Washington, 10 dez. 1932. Seção de Documentos Pessoais, Instrumento de busca do Fundo Bertha Lutz. [BR.AN.RIO.Q0. BLZ.COR.TXT.1932.18]. Como essa seção do Arquivo Nacional est em organização, não pude averigua se Lutz respondeu ao convite. (ARQUIVO NACIONAL.... 1912 1975).

${ }^{18} \mathrm{Em}$ suas memórias, Lutz registrou desta forma a audiência que as feministas tiveram com Getúlio Vargas no segundo semestre de 1931: "Comparecemos audiência, que foi ainda no velho Palácio do Catete, apresentamos a sugestão de que desejávamos o voto para a mulher brasileira, com toda a plenitude e em todo o País. E o senhor Getúlio Vargas prometeu dar o voto e mais tarde cumpriu a
Trata-se de um tema ainda pouco explorado pela historiografia da política externa e ainda menos considerado na historiografia do feminismo. Ainda assim, já se observam contribuições expressivas para elucidar a relação entre a política externa dos EUA e seus grupos empresariais. ${ }^{14}$ Como parte dos preparativos da conferência de Montevidéu, a fundação Carnegie enviou ao Itamaraty, em julho de 1931, um ofício solicitando informações do Governo brasileiro sobre a condição jurídica da mulher no país. ${ }^{15}$

A solicitação da Carnegie recebeu o tratamento de correspondência oficial e foi respondida pelo Itamaraty em 15 de outubro daquele ano, a partir das informações prestadas pelo Ministro da Justiça, Oswaldo Aranha. Aranha informara ao Itamaraty que o governo havia nomeado uma comissão de juristas para rever a legislação brasileira, logo, o assunto dos direitos das mulheres estava em fase de discussão. Acrescentou ainda que se cogitava conceder o direito de voto à mulher. ${ }^{16}$

Em seus rascunhos pessoais e memórias gravadas, Bertha não se recorda da ligação entre a Carnegie e o NWP, no entanto, a convite dessa fundação, Lutz percorreu os Estados Unidos em 1932 para estudar o sistema de museus desse país e, em dezembro do mesmo ano, foi convidada a trabalhar no Instituto Americano de Direito Internacional, organização sediada em Washington e patrocinada pela fundação Carnegie. ${ }^{17}$ Ora, se a decisão de Getúlio de franquear o sufrágio às mulheres respondeu a alguma influência externa, as memórias das feministas da Federação Brasileira pelo Progresso Feminino (FBPF) - tanto a de Carmen Portinho como a de Bertha Lutz - não confirmam. ${ }^{18}$ Também a interpelação do Itamaraty pela Carnegie não é comentada por Lutz, embora todos os atores conhecessem uns aos outros, logo, é razoável pensar que a feminista estivesse inteirada da iniciativa do Instituto Americano; tampouco Stevens oferece crédito ao apoio da Carnegie na tarefa de coligir a legislação civil dos 21 países do Interamericanismo. Para o público interno da NWP, Stevens valorizava seu papel central na missão de conduzir a pesquisa sobre as leis civis no Continente sem reconhecer publicamente o apoio que o NWP recebia das fundações privadas. Essa visão personalista acerca da campanha do NWP em favor do igualitarismo nas Américas ainda repercute na historiografia norte-americana sobre o assunto, que não dá muita atenção ao leque das articulações políticas do grupo feminista abrigado na entidade. ${ }^{19}$

De toda forma, em Montevidéu, a Comissão Interamericana de Mulheres fez uma nova investida em direção à plena igualdade de direitos entre homens e mulheres em todo o Continente, a exemplo do que haviam tentado na conferência de 1928 e do programa de ação que as 
promessa. Naquela ocasião, a senhora Maria Eugênia Celso Ihe disse com muita gentileza: "Estamos disposição de Vossa Excelência para servi-lo com toda a satisfação, não , Bertha? E eu respondi: "Sim, Maria Eugênia, em tudo o que for de interesse do País. Parece que eu j adivinhava naquela ocasião que, com o senhor Getúlio Vargas, era a boa tática gaúcha ser franca e dizer as coisas como são. (Anotações para o projeto de livro sobre a história do feminismo, 8/3/1971. Registros sonoros, fundo FBPF [BR.AN.RIO.QO.BLZ.APR.ELC.DSO.11] (ARQUIVO NACIONAL..., 1971). Carmen Portinho também associa a conquista do voto feminino no Código Eleitoral de 1932 ao diálogo que as feministas conseguiram manter com o Presidente Vargas. Ver: Geraldo ANDRADE, 1999.

${ }^{19}$ Ver: Christine BOLT, 2004, p. 68. A autora afirma que Stevens se queixava de estar sobrecarregada de trabalho: controlar a correspondência, levantar fundos, pesquisar a legislação. ${ }^{20}$ BECKER, 1981.
21 "Homens e mulheres devem ter direitos iguais em todos os Estados Unidos e em todo lugar sujeito sua jurisdição. (BECKER, 1981, p. 18). feministas do NWP seguiam no âmbito da política doméstica norte-americana. Lá, as ativistas do NWP sofriam feroz oposição das chamadas feministas sociais, ou reformistas. Nesse sentido, a arena internacional é mais uma face das profundas divergências internas entre os grupos feministas nos EUA, com repercussões sobre o incipiente movimento feminista nos países latinos. Eis por que, no Uruguai, os grupos feministas travaram uma batalha paralela à conferência, que, ao mesmo tempo, refletia os embates que traziam de cada cena doméstica.

Em outros termos, considerar as ações individuais das feministas integrantes das delegações como dissociadas da política externa de seus países é um grave equívoco de interpretação. Por essa razão, examino agora as propostas dos grupos feministas e a forma como foram defendidas durante a conferência.

\section{Uma conferência paralela: os feminismos em conflito}

O National Woman's Party era um grupo de pressão, originado de uma dissidência da principal entidade feminista que atuou pelo sufrágio nos Estados Unidos, nos anos 1910. Essa entidade era a National American Women Suffrage Association, liderada por Carrie Chapman Catt. ${ }^{20}$

Após o sucesso da emenda constitucional garantindo o direito de voto a todas as mulheres norte-americanas, o grupo de Catt assumiu nova estratégia, com ênfase na educação política das mulheres, e, para isso, criou-se a League of Women Voters, constituída basicamente pelas mesmas integrantes. Além disso, o grupo pressionou o Legislativo por reformas pontuais nas condições de trabalho das mulheres. Já as feministas do NWP prosseguiram na estratégia de pressão cerrada sobre o Congresso para fazer passar outra emenda constitucional, destinada a eliminar de vez toda forma de desigualdade de gênero no país. $A$ redação do texto da emenda e a campanha em seu favor couberam a Alice Paul. Eis a emenda apresentada ao Legislativo norte-americano, em 1923: "Men and women shall have equal rights throughout the United States and every place subject to its jurisdiction." 21

As divergências entre os grupos se estendiam além das estratégias de ałuação política, uma vez que as feministas da League estavam mais próximas do campo político do Partido Democrata, ao passo que as ativistas do NWP tinham mais afinidade com $\circ$ Partido Republicano, fosse por relações políticas, fosse por origens e status pessoais. Muito embora todas negassem a filiação a partidos políticos, porque acreditavam que a colaboração com a política partidária compro- 
${ }^{22}$ Leila RUPP, 1998.

${ }^{23}$ BOLT, 2004, cap. 4. metia a sua identidade feminista, a verdade é que as pessoas transitavam por meios políticos distintos, buscavam apoio e financiamento em grupos políticos diferentes, além de terem maior afinidade ideológica com integrantes do campo democrata ou republicano.

Por tais razões, a controvérsia em torno da emenda da Igualdade dos Direitos, aliás, derrotada em 1923, estava inserida no debate político doméstico norte-americano em torno de questões profundas: o modelo de federalismo, implicando o grau de autonomia dos estados para adotarem políticas segregacionistas e, sobretudo, o debate em torno da regulação do trabalho feminino e a proteção à maternidade. Se prevalecesse o entendimento da igualdade absoluta entre os sexos, temiam as feministas sociais que as trabalhadoras perderiam toda forma de proteção contida nas leis arduamente arrancadas dos Legislativos, tanto no plano federal quanto nos estados. As feministas do NWP, por sua vez, sustentavam que a igualdade, pela via constitucional, abreviava o caminho para a supressão de todas as desigualdades de gênero que persistiam nos estados. Superadas as restrições legais, as mulheres teriam livre acesso ao mercado de trabalho, diziam as feministas do NWP, em sua maioria, profissionais liberais.

No entanto, a situação da mulher no mercado de trabalho não provocava a polarização das opiniões apenas entre as feministas, pois os sindicatos dominados por homens queriam reformas protetoras que pudessem tirar as mulheres do chão das fábricas - a exemplo de leis restritivas quanto a ofícios e horários - e assim excluí-las da competição por postos de trabalho. Já os governos no interguerras temiam que a competição econômica desigual assumisse a forma de legislação protetora da mão de obra feminina e, por isso, promoviam negociações para alinhar os países industrializados em termos de grau de proteção às trabalhadoras. ${ }^{22}$

Dessa forma, a controvérsia sobre a igualdade versus proteção polarizou o campo político feminista nos EUA e transbordou para fora do país. Para se fortalecerem internamente, os grupos feministas buscaram alcançar visibilidade internacional e atuar junto às esferas diplomáticas, a fim de fazer valer seus pontos de vista. Por afinidade quanto a plataformas e à cultura política, as feministas lideradas por Carrie Catt estavam mais próximas das britânicas, particularmente, da International Alliance of Women, liderada por Margery Ashby.

Nos anos 1920, Catt e Ashby estabeleceram uma entente mútua, de modo a que a primeira recuasse do projeto de ganhar posições na Alliance em um momento em que o feminismo europeu padecia de restrições financeiras e apresentava fraco potencial para se expandir, contrariamente ao observado nos EUA. ${ }^{23}$ Simultaneamente, as líderes bloquearam 
24 RUPP, 1998.

25 Diva Nolf' NAZARIO, 1923.

26 ARQUIVO NACIONAL..., 1938. Sumário da Ata da FBPF de 26 de abril de 1938. (Instrumento de busca da seção Documentos Pessoais, fundo FBPF).
27 BOLT, 2004. De modo similar a Bolt, Becker escreve que Catt não teve energia para sustentar a posição de liderança no movimento feminista latinoamericano, abrindo-se, assim espaço para a o NWP. Ver: BECKER 1981 , p. 171 . Sobre o movimento de mulheres na Argentina, ver, entre outras: Adriana María VALOBRA, 2010.

${ }^{28}$ RUPP (1998) e BOLT (2004)

discutem $O$ sentimento de superioridade pedagógica que embalava as feministas ocidentais então (RUPP, 1998; BOLT, 2004). a tentativa do NWP de avançar na Europa, ao negarem a filiação do NWP à Alliance, em 1926. ${ }^{24}$ Acelera-se, então, a corrida das feministas norte-americanas para ganhar posições na América Latina, na esteira da diplomacia dos Estados Unidos para o Continente, aproximando-se dos grupos de mulheres que começavam a surgir nos países da região. De fato, Carrie Catt foi a oradora de honra da primeira conferência feminista organizada pelo grupo de Bertha Lutz, em 1922. Do Rio de Janeiro, Catt seguiu para São Paulo, onde foi recebida pelas integrantes da seção paulista da FBPF e, posteriormente, continuou viagem até a Argentina. ${ }^{25}$ Após a visita de Catt, Bertha Lutz assumiu a tarefa de promover o pan-americanismo no Brasil, em colaboração com o embaixador dos Estados Unidos. Assim, a 12 de outubro de 1925, celebrou-se pela primeira vez o dia Pan-Americano, no Clube de Engenharia, com a presença de feministas da Federação, do embaixador dos EUA e dos ministros da Venezuela e do Paraguai. Nos anos seguintes, a experiência foi repetida, sem grande repercussão, até que, em 1938, sob circunstâncias políticas inteiramente distintas, o ltamaraty abrigou a celebração do pan-americanismo em seus salões. ${ }^{26}$ Nesse meio tempo, as ativistas do NWP, como já se comentou, colaboraram intensamente com a diplomacia dos Estados Unidos.

Entretanto, à arena da cooperação interamericana, as feministas do norte levavam consigo o que havia de melhor e de pior na imagem dos Estados Unidos Unidos diante da opinião pública latina: a simpatia pelos avanços econômicos e direitos das mulheres, e a desconfiança quanto aos métodos e as intenções. Por tais razões, discordo da leitura que as historiadoras do feminismo norte-americano fazem sobre a aproximação de feministas do norte a irmãs latinas. A opinião de Bolt, por exemplo, é de que a América Hispânica e o Brasil eram reserva natural para a expansão dos grupos feministas norte-americanos, o que não corresponde ao exame da documentação relativa à conferência de Montevidéu, às atitudes de Bertha Lutz, tampouco à historiografia do feminismo na região. ${ }^{27}$ Observa-se, ao contrário, que a adesão dos grupos locais às propostas das feministas do norte foi negociada $e$ nada automática.

O mal-estar guardava relação com a atitude de superioridade das feministas europeias e norte-americanas. Em verdade, as feministas europeias e norte-americanas sentiam ser sua missão apresentar às sociedades incultas e atrasadas as virtudes do progresso das relações de gênero. ${ }^{28}$ Julgavam ser capazes de inspirar as irmãs oprimidas. E as interlocutoras que tratassem de entender o recado e adotar novos comportamentos, caso contrário, haveriam de sentir o peso da palavra das sisters do norte. Essa foi a leitura que uma cubana fez da controversa líder do NWP, Doris Stevens. Esta, se contrariada, 
${ }^{29}$ BOLT, 2004, p. 68.

${ }^{30}$ BOLI, 2004.

${ }^{31}$ Report of the Inter American Commision of Women to the Seventh International Conference of American States on the Civil and Political Rights of Women. Montevideo, December 1933 Anexado ao Dossi: "VII Conferencia, a Interamericana Montevideo, 1933. Direitos da Mulher propostas. [962 VII, I. 1.417, m. 32.809, AHI]. (ARQUIVO HISTÓRICO..., 1933a, p. 26-27). 32 SEVENTH INTERNACIONAL CONFERENCE OF AMERICAN STATES, 1933. Third Committee. Civil and Political Rights of Women. Minutes and Antecedents. Montevideo, 1933. Anexado ao Dossi: "VII Conferência, a Interamericana, Montevideo, 1933. Direitos da Mulher propostas. [962 VII, I. $1.417, \mathrm{~m} .32 .809, \mathrm{AHI}$. (ARQUIVO HISTÓRICO..., 1933a, p. 26-27). abandonava facilmente a cordialidade calculada e conduzia impositivamente as discussões. ${ }^{29}$ Mesmo a moderada Carrie Catt recomendava prudência e atitude conservadora às colaboradoras que travassem contato com mulheres latinoamericanas, sobretudo, recomendava-lhes evitar temas mais controversos com respeito à família e aos costumes. ${ }^{30}$

Nesse quadro de incompreensões mútuas, a Comissão Interamericana de Mulheres preparou para a conferência um estudo sobre a condição jurídica das mulheres nas Américas, uma proposta de convenção sobre a nacionalidade da mulher casada, e, sobretudo, um Tratado de Igualdade de Direitos entre homens e mulheres. ${ }^{31}$ Em contrapartida, a delegada do Uruguai, Sofia Alvarez Vignoli de Demicheli, apresentou um projeto de unificação da legislação de direitos civis e políticos das mulheres nas repúblicas americanas com ênfase na capacidade jurídica da mulher casada, questões relativas ao pátrio poder, direitos de viúvas e de companheiras. Pelo Brasil, Bertha Lutz propôs um projeto de teor similar ao da delegada uruguaia (Quadro 1). ${ }^{32}$

Quadro 1- Direitos civis e políticos da mulher: proposta de reivindicações mínimas apresentada pela assessora técnica da delegação brasileira, Bertha Lutz.

1. Abolição de todas as restrições da capacidade jurídica, econômica e política da mulher, especialmente:

a) revogação dos textos legais que limitam a capacidade da mulher casada;

b) princípio do igual trabalho, igual salário, sem distinção de sexo ou estado civil.

1. Igualdade completa de direitos entre ambos os sexos.

2. Nacionalidade independente da mulher casada.

3. Seguro maternal.

4. Na elaboração de leis concernentes ao lar, à maternidade, à infância e ao trabalho feminino, é obrigatória a consulta à mulher, por intermédio de associações femininas representativas.

5. Nos sindicatos em cujo quadro social existirem mulheres, é obrigatória, por lei, a inclusão de, ao menos, uma mulher na direção.

6. Na legislação de funcionários públicos será assegurada a igualdade de condições aos cidadãos, sem distinção de sexo ou estado civil e mantidas as disposições da lei de licença referente à maternidade.

Fonte: SEVENTH INTERNACIONAL CONFERENCE OF AMERICAN STATES, 1933.

Os esforços de Bertha e de Demicheli buscavam mostrar a capacidade propositiva das mulheres dos países latinos, evitando assumir o papel de meras expectadoras das iniciativas das norte-americanas. Ao mesmo tempo, contornavam a proposta da igualdade absoluta entre os sexos, notoriamente inaceitável para a maior parte dos 
33 "A Comissão Interamericana de Mulheres acredita fortemente que a questão da igualdade de oportunidades para as mulheres transcende fronteiras dos estados nacionais. No modo mais concreto, a questão envolve os verdadeiros fundamentos da liberdade humana [...]. Os países estabelecidos neste hemisfério estão vinculados entre si por uma comunidade cultural e de ideias. Nenhuma nação pode esperar, por si só, elevar os padrões de igualdade para as mulheres, ou, de fato, qualquer outro padrão, $e$ permanecer isenta de influência de seus vizinhos. (Report of the Inter American Commision of Women to the Seventh International Conference of American States on the Civil and Political Rights of Women. Montevideo, December 1933). Anexado ao Dossi: "VII Conferencia, a Interamericana, Montevideo, 1933. Direitos da Mulher propostas. [962 VII, I. 1.417 m. 32.809, AHI]. (ARQUIVO HISTÓRICO..., 1933a, p. 6).

${ }^{34}$ Report of the Inter American Commision of Women to the Seventh International Conference of American States on the Civil and Political Rights of Women. Montevideo, December 1933. Anexado ao Dossi: "VII Conferencia, a Interamericana, Montevideo, 1933. Direitos da Mulher propostas. [962 VII, I. 1.417, m. 32.809, AHI]. (ARQUIVO HISTÓRICO..., 1933a, p. 6).

${ }_{35}$ Proposicion de la delegacion de Brasil sobre derechos civiles y políticos de la mujer.Documento datilografado e anexado ao Dossi: "VII Conferencia, a Interamericana, Montevideo, 1933). Direitos da Mulher propostas. [962 VII, I. 1.417 , m. 32.809, AHI] (ARQUIVO HISTÓRICO..., 1933a, p. 3).

36 "A Sétima Conferência Pan Americana concorda em recomendar aos governos das repúblicas das Américas que procurem, dentro do possível e nas circunstâncias mais cômodas para a situação peculiar de cada uma delas, estabelecer as maiores igualdades entre homens e mulheres em tudo o que se refira posse, ao gozo e países representados na conferência. Ambos os projetos, o de Bertha e o da delegada uruguaia, foram encaminhados à Comissão de Mulheres para estudo.

Tão controverso era o tratado, no âmbito diplomático interamericano e na política doméstica do próprio país de origem da presidente da comissão, que o caminho de sua discussão ensina muito sobre as posições políticas em conflito nos bastidores de Montevidéu.

Para vê-lo aprovado, de pouco serviu o apelo emocional da Comissão Interamericana de Mulheres em favor da integração dos direitos civis das mulheres no Continente, como se observa, exemplarmente, no fecho do documento produzido pela Comissão: ${ }^{33}$

The Inter American Commission of Women strongly believes that the question of equality of opportunities for women transcends the frontiers of national States. In the most concrete manner, it involves the very fundamentals of human liberty [...]. The countries established on this hemisphere are bound together by a certain community of culture and ideas. No single nation can hope, by itself, to set up standards of equality for women, or indeed any other standards, which remain unaffected by its neighbors.

Para encaminhar a discussão do tratado, a Comissão Interamericana de Mulheres redigiu uma proposta de redação de tratado bastante impositiva: ${ }^{34}$

Los Estados contratantes convienen en que, a partir de la fecha de la ratificación de este tratado, los hombres y las mujeres tendrán derechos iguales en todo el territorio sometido a sus respectivas jurisdicciones.

Em resposta, a delegação do Brasil, com assistência de Bertha Lutz, redigiu outra versão para o texto: ${ }^{35}$

La VII Conferencia Panamericana recomienda a todos los Gobiernos de las Republicas de América que procuren dentro de lo posible y en el más breve plazo, establecer la igualdad del hombre y de la mujer en todo cuanto se refiera a la posesión, goce y ejercicio de los derechos civiles y políticos.

Ao notório tom impositivo e ofensivo aos princípios do Direito Internacional da proposta da Comissão Interamericana de Mulheres, o delegado do Chile respondeu com outra redação para o tratado, ainda mais cautelosa do que a proposta pelo Brasil: ${ }^{36}$

La Septima Conferencia PanAmericana acuerda recomendar a los gobiernos de las Republicas de America que procuren dentro de lo posible y en la más cômodas circunstancias para la situacion peculiar de cada una 
ao exercício dos direitos civis e políticos. Recomendaciones de Gustavo Rivera. Presidente de la sub comision y delegado de Chile, em 14 de dezembro de 1933 Incluído em: Dossi "Direitos da Mulher, 1931-1939 [502.63, 1.237, m. 27.551, AHI.] (ARQUIVO HISTÓRICO..., 1933a, p. 19, grifo meu).

${ }^{37}$ Discurso transcrito, com trechos suprimidos, por: SOIHET (2006, p. 151). Supõe-se que Soihet tenha consultado este documento no Arquivo Nacional.
${ }^{38}$ Objeção semelhante do delegado chileno foi levantada na Câmara dos Deputados, no Brasil, durante a discussão de um projeto de lei relativo aos direitos jurídicos das mulheres casadas, em 1952 Ver: Teresa Cristina de Novaes MARQUES e Hildete Pereira de MELO, 2008.

${ }^{39}$ VII International Conference of American States. Third Committee, Civil and Political Rights of Women. Minutes of the Fourth Session, 16 de dezembro de 1933. [Folheto arquivado em: Dossi "Direitos da Mulher, 1931-1939 [502.63, 1.237, m. 27.551, AHI.]. (ARQUIVO HISTÓRICO..., 1933, p. 11).

40 "A atitude da delegação norteamericana não causou apenas lamento e desapontamento, mas também profundo choque e surpresa. (BECKER, 1981, p. 183.)

${ }^{41}$ BECKER, 1981, p. 183-185. de elas, estabelecer las mayores igualdades entre hombres y mujeres en todo lo que se refiere a la posesion, goce y ejercicio de los derechos civiles y políticos.

Mesmo contrária à proposta de Stevens, Bertha tomou a palavra durante os trabalhos da subcomissão para expressar com clareza a dificuldade de se traduzir os esforços diplomáticos em mudanças legais efetivas na cena doméstica: ${ }^{37}$

Tendo ouvido aqui, Senhor Presidente, da parte da V. Ex., outra objeção. A de que os direitos civis e políticos da mulher constituem matéria de direito interno e não de assunto de direito internacional [...]. Na realidade, Senhor Presidente, estamos diante de um dilema porque ou os tratados versam sobre assuntos satisfatoriamente resolvidos e se tornam supérfluos, ou então se alega que são impossiveis porque modificam as leis [...].

Lutz concluiu sua fala conclamando os conferencistas a se empenharem para acelerar as reformas legais nos seus respectivos países, de modo a igualar os direitos civis, sociais e políticos das mulheres de todo o Continente. ${ }^{38}$

Todo empenho em defesa da tese do igualitarismo não foi suficiente para salvar o tratado. Para selar a sorte do documento, foi decisiva a posição anunciada pela representação norte-americana na sessão de 16 de dezembro de 1933. O delegado norte-americano, Weddell, tomou a palavra para dizer que a administração Roosevelt reconhecia o valor do relatório produzido pela Comissão Interamericana de Mulheres, mas que o seu governo estava empenhado em rever a legislação desigual e, mais importante, entendia ser o assunto próprio da competência dos governos de cada Estado da federação, ao invés de ser matéria federal. ${ }^{39}$ Nesses termos, anunciou Weddell que a delegação dos Estados Unidos se absteria de votar a proposta do Tratado de Igualdade, o qual, de fato, foi assinado apenas pelos representantes do Uruguai, do Paraguai, do Equador e de Cuba.

Contrariada com o curso da discussão, Stevens fez valer as fortes conexões do NWP com a imprensa da Costa Leste para criticar a posição assumida pela delegação dos EUA em Montevidéu: "the attitude of the US delegation was not only a matter of great regret and disappointment, but came as a profound shock and surprise." 40

Já as feministas da League of Womens Voters tiveram que negar em comunicado publicado no New York Times que Eleonor Roosevelt tivesse lançado mão de sua influência no Partido Democrata para evitar que os Estados Unidos se comprometessem com o tratado proposto pelo NWP. ${ }^{41}$ De toda forma, Stevens ficou isolada e perdeu apoio no Departamento de Estado, no qual a pressão democrata fez da confiável feminista social, Mary Winslow, ligada ao Women's Bureau, a 
42 "Ainda luto valentemente, desejo fazer continuar o movimento aqui e trabalhar pelo pan-americanismo novamente. Você soube alguma coisa de Montevidéo por intermédio da senhorita Breckinrdige? A senhorita Stevens deu uma pequena demonstração de sua psicopatia sexual louca agradando os delegados do México com beijos e votando contra nós, atraindo os haitianos com a sua secretária francesa, que personifica a reputação que as mulheres francesas têm na América do Sul. O problema que os homens foram para casa com a ideia de que tanto a senhorita Breckinrdige quanto eu somos assexuadas [...]. (Carta de Bertha Lutz a Carrie Chapman Catt, 12 fev. 1934. [AP 46, Cx 55, Pact 4, Doc 5; COR 1934-3.1 E 3.2] (ARQUIVO NACIONAL..., 1934). Agradeço pesquisadora gaúcha Mônica Karawejczyk a permuta desse documento.

43 "Essas pessoas do Partido das Mulheres têm a mentalidade distorcida e dizem coisas más sobre a Liga das Mulheres Eleitoras, mas a Liga não se importa. (Carta de Catt a Lutz, 26 mar. 1934 [AP 46, Cx 55, Pct 4, Doc. 16; COR 1934-4]. Documento obtido igualmente por intermédio de Mônica Karawejczyk).

${ }^{44}$ A Noite, 6 jan. 1934. Anexado ao Dossi: "VII Conferência Internacional Americana, Montevideo, 1933 [962.VII, 9.279, AHI] (ARQUIVO HISTÓRICO..., 1934b).

${ }^{45}$ Anotações para o projeto de livro sobre a história do feminismo, iniciadas em 8 de março de 1971 Registros sonoros de Bertha Lutz, fundo FBPF. [BR.AN.RIO.QO.BLZ.APR. ELC.DSO.11] (ARQUIVO NACIONAL..., 1971). vice-presidente da Comissão Interamericana de Mulheres em 1939. A presidência coube, então, a uma feminista dominicana. Já a pauta do igualitarismo foi eliminada das discussões da conferência interamericana de Lima, em 1938.

Antes de cair, porém, Doris Stevens não poupou palavras para expressar a Bertha e a outra feminista norte-americana, Mrs. Breckindidge, também estreitamente ligada a Catt, o que pensava sobre a conduta de ambas durante a conferência. Pelo que relatou Bertha a Catt, a quem se referia como dear mother, as coisas ficaram feias nos bastidores de Montevidéu: ${ }^{42}$

Still I am fighting valiantly and want to keep the movement here going and work up the panamerican again. Did you hear anything of Montevideo, from Miss Breckinrdige? Miss Stevens gave a little demonstration of a sex mad psychopath, calling Miss Breckinrdige and me by zoologic names, of a domestic variety, paying the Mexican delegates in kisses for voting against us, luring the haitians with a French secretary she has who lives up to the reputation French women have in South America. The trouble is the men went home with the idea that Miss Breckinrdige and I were sexless [...] [ilegível].

Assim respondeu Catt a Lutz, em 26 de março de 1934: "Those Women's Party people have queer notions and say some quite mean things about the League of Women Voters, but the League of Women Voters does not seem to mind." 43

Para Stevens, Bertha e Breckinrdige eram animais desprezíveis; estas, por sua vez, consideravam Stevens uma pervertida sexual. Catt tinha as feministas do NWP por maldosas e achava que elas pensavam de modo estranho. Nem por isso, Bertha relatou as divergências ocorridas durante a conferência quando concedeu numerosas entrevistas à imprensa do Rio. Declarou ela ao jornal $A$ Noite: ${ }^{44}$

O ambiente que encontrei na VII Conferência Panamericana de Montevideo não apresentou nenhum indício de hostilidade ao feminismo. Havia, é certo, delegações absolutamente indiferentes à causa, mas, em compensação, outras houve, como a dos Estados Unidos e a de Cuba, que defenderam com ardor e entusiasmo os direitos da mulher.

O uso do feminismo no singular é notoriamente tático, na linha de interpretação acertadamente desenvolvida por Soihet. Relatar ao público masculino as divergências internas nos feminismos era impensável. Entretanto, a insistência no uso do singular assumiu, ao longo dos anos, a característica de autoilusão, e Bertha, já bem idosa, continua a se referir ao movimento de mulheres dessa forma. ${ }^{45}$ 
${ }^{46}$ Ressalte-se que a proposta de se incluir necessariamente mulheres nas delegações sofreu ataques em plenário e foi defendida pelo delegado, Dr. Carlos Chagas, amigo próximo do pai de Bertha Dr. Adolfo Lutz. Também o chefe da delegação, Afrânio de Mello Franco, saiu em defesa das propostas da feminista. Já a proposta de reformulação do estatuto da Comissão Interamericana de Mulheres não avançou nos anos seguintes no sentido imaginado por Bertha. Ver: Seventh Internacional Conference of American States. Third Committee. Civil and Political Rights of Women. Minutes and Antecedents. Montevideo, 1933, p. 11. Anexado ao Dossiê: "VII Conferência, a Interamericana, Montevideo, 1933. Direitos da Mulher - propostas." [962 VII, I. 1.417, m. 32.809, AHI] (ARQUIVO HISTÓRICO..., 1933a).

${ }^{47} \mathrm{Ao}$ voltar ao Brasil, Bertha concedeu entrevistas aos seguintes jornais: Diário de Notícias (12 jan. 1934), A Noite (6 jan. 1934 e 12 jan. 1934), Correio da Manhã (12 jan. 1934) e Folha da Manhã (7 jan. 1934).

${ }^{48}$ RUPP, 1998, cap. 4

${ }^{49}$ Há no Arquivo da Câmara dos Deputados telegramas, manifestos e abaixo-assinados, enviados por grupos feministas de todo o país a Getúlio Vargas durante o mês de julho de 1932, solicitando que Bertha Lutz fosse nomeada integrante da Comissão de Elaboração do Anteprojeto. [A 1933/34 2:894, m:2, p: 1, J:3]. (ARQUIVO DA CÂMARA..., 1933-1934, p. 1).

50 Bertha LUTZ, 1933, p. 39

\section{Bertha Lutz: igualitarismo ou reformismo?}

A despeito de todo o desgaste pessoal, a participação de Bertha na conferência de Montevidéu resultou em bons frutos. Primeiramente, Lułz propôs, com o apoio da delegação do Brasil, duas resoluções aprovadas em plenário: o compromisso de que, nas próximas conferências, os governos indicassem delegadas plenipotenciárias para atuar conjuntamente com os delegados, além da proposta de reformular os estatutos da Comissão Interamericana de Mulheres de modo que a entidade assumisse um caráter executivo e voltado para fiscalizar as condições de trabalho das mulheres nas Américas ${ }^{46}$ Somada a essas vitórias na arena diplomática, a cobertura da conferência na imprensa deu maior visibilidade às propostas da FBPF na arena política doméstica. ${ }^{47}$

Como se posicionava Lutz perante o debate político que dividia o movimento feminista norte-americano em dois campos antagônicos? Qual a saída para superar a condição subalterna das mulheres: o igualitarismo ou o reformismo?

Com certeza, Bertha manteve fortes laços de amizade com Carrie Catt, assim como outras tantas mulheres construíram sua identidade feminista por admirarem e seguirem a líder Alice Paul. Nesse particular, Rupp oferece a contribuição mais sugestiva sobre a construção das identidades feministas, feita a partir de fortes ligações pessoais entre as ativistas dos vários grupos de mulheres. ${ }^{48}$ Por tais razões, Bertha foi influenciada pelas ideias do feminismo reformista, também denominado na historiografia norte-americana de feminismo social. Defendia, portanto, a proteção ao trabalho feminino, a assistência estatal à maternidade e à infância. Mas não apenas isso.

Quando surgiu a oportunidade de formular uma nova Constituição, Bertha Lutz e suas colaboradoras usaram seus recursos políticos para que a primeira fosse nomeada integrante da comissão de notáveis responsável pela elaboração do anteprojeto da Carta. ${ }^{49}$ Durante os trabalhos da Comissão, Bertha publicou um livro de sugestões ao texto da Constituição. Trata-se de um trabalho alicerçado em princípios, sendo o oitavo dedicado à equiparação dos sexos. Lutz defendeu que a nova Constituição assumisse o compromisso com a igualdade entre os sexos por razões de justiça com a metade da população, nos seguintes termos: ${ }^{50}$

A República não reconhece privilégios de classe, de nascimento ou de sexo. Salvo para efeitos militares, a expressões referentes a pessoas abrangem o homem e a mulher. São abolidas todas as restrições à capacidade jurídica, econômica e política da mulher. Não serão permitidas discriminações legislativas, contrarias à mulher, baseadas no sexo ou no estado civil. 
${ }^{51}$ Cecília MEIRELES, 1939, p. 107

${ }^{52}$ Almerinda Faria GAMA, 1984.
Assim como Alice Paul guiara o NWP para pressionar o Congresso norte-americano em busca da aprovação da emenda dos Direitos Iguais, em 1923, Bertha vislumbrou, no momento político que o Brasil vivia, a possibilidade de fazer inscrever na nova Constituição o compromisso da igualdade entre homens e mulheres.

Diferentemente das feministas do NWP, porém, Bertha associava a agenda do igualitarismo com muitas propostas de reformas da condição jurídica e social das mulheres no Brasil. Além disso, a partir do modelo da entidade norteamericana, Women's Bureau, Bertha propôs a criação do Departamento Nacional da Mulher, durante o seu mandato parlamentar, em 1937.

Fosse pela via da pressão direta sobre os governantes e parlamentares, fosse pela via da negociação no âmbito do Legislativo durante o exercício de seu mandato na Câmara Federal, Lutz lançava mão de todos os recursos políticos para obter reformas na condição de vida das mulheres. ${ }^{51}$ Guiadas pelo sentido de oportunidade e de urgência, as feministas da FBPF desejavam colher resultados imediatos. Como recordou a colaboradora da FBPF, Almerinda Gama: "- Não podíamos perder qualquer oportunidade!"52

A proteção estatal, e não a assistência caritativa ao trabalho feminino, estava certamente entre as prioridades das feministas da FBPF. Daí por que, encerrados os trabalhos constituintes, as feministas buscaram pressionar para que fossem regulamentados os capítulos da carta que tratavam da ordem social. Pretendiam elas, sobretudo, assegurar garantias para o emprego das mulheres em face do casamento e da gestação.

Assim, a proteção ao trabalho também estava no centro da agenda política feminista no Brasil, ainda que o cotidiano das integrantes da FBPF estivesse distante da realidade vivida pelas mulheres trabalhadoras, isto é. aquelas que trabalhavam para sobreviver e não ambicionavam construir carreiras. ${ }^{53}$ Tanto assim era que, em março de 1936, Bertha escreveu conclamando as leitoras de classe média a se sensibilizarem com o sofrimento das trabalhadoras, sujeitas ao desemprego por motivos arbitrários. Disse ela: ${ }^{54}$

\section{E nós mulheres, o que devemos fazer?}

Aquiescer? - consentirem aquelas cuja renda individual, emprego público vitalício, ou situação de família Ihes garante a subsistência, em que seja explorado o trabalho das outras, ou que irmãs nossas sejam atiradas à fome, à prostituição e à mendicância? Desviar os olhos para não vê-las recalcadas novamente à servidão dos comuns afazeres domésticos, numa época como 
${ }^{55}$ CORREIO DA MANHÃ, 12 jan 1934. Anexado ao dossi "VII Conferência Internacional Americana Montevideo, 1933 [962 VII 9.279]. (ARQUIVO HISTÓRICO..., 1933b).

${ }^{56}$ Deborah G. WHITE, 1999. a nossa, em que o lar abastado cada vez mais se simplifica, graças aos progressos da eletricidade, enquanto o lar pobre é reduzido pela miséria até o ponto em que deixa de existir?

Jamais.

Bertha buscava, assim, aproximar as mulheres que acompanhavam as atividades da FBPF, fossem aquelas que compareciam às reuniões e conferências organizadas pela entidade, fossem as leitoras dos boletins feministas, das mulheres trabalhadoras. A força política das mulheres de classe média podia, supunha Lutz, reduzir os abismos sociais e oferecer outra via política para os trabalhadores, fora dos marcos ideológicos da esquerda.

Não por acaso, Bertha traça um paralelo entre o varguismo incipiente e as medidas propostas por Roosevelt desde o início da sua gestão, em março de 1933. Logo após a conferência do Uruguai, ela declarou ao jornal Correio da Manhã que o New Deal colocara em curso uma "revolução pacífica" no sistema políico norte-americano. ${ }^{55}$ De fato, naqueles anos, muitos grupos políticos, a exemplo de ativistas negras, apostaram que os seus interesses seriam atendidos diretamente pelo Estado, fora da arena legislativa, habitualmente pouco sensível às questões que afligiam as minorias. ${ }^{56}$

No entanto, para os padrões da política feminista norte-americana, a combinação de elementos da agenda igualitarista com um forte peso da agenda reformista era pouco usual. Mas foram essas as escolhas de Bertha. Escolhas coerentes com a leitura que as feministas faziam do sistema político brasileiro, sobretudo, do papel central da Presidência nesse sistema, especialmente após 1930.

Há que se considerar também que Lutz podia ousar propor o igualitarismo na Constituição brasileira porque, aqui, as desigualdades de gênero não se somavam às desigualdades raciais. Não significa dizer que não houvesse profundas desigualdades raciais no Brasil de então, apenas, que elas não estavam inscritas na ordem legal, tampouco compunham, como nos EUA, um elemento crítico do sistema federativo. A forma difusa do racismo no Brasil constituía, assim, um obstáculo político a menos a se superar.

\section{Considerações finais}

Propus examinar aqui o debate político em torno do igualitarismo versus reformismo que as feministas travaram entre si nos bastidores da Conferência Interamericana de Montevidéu. Examinei também a estratégia adotada por Bertha Lutz quando esta colaborava com o ltamaraty. Qual a razão para esse esforço em ocupar posições também na política externa do país? Porque Lutz, além de estreitar as 
alianças com suas interlocutoras estrangeiras, calculava obter significativos ganhos políticos ao participar de espaços diplomáticos, principalmente porque os compromissos assumidos na cena internacional ganhavam expressiva visibilidade na imprensa, algo favorável ao movimento feminista no país. Ao mesmo tempo, esses compromissos estabeleciam uma agenda de discussão diplomática e, com esperança, constrangiam o sistema político doméstico a admitir a existência dos problemas e, a partir disso, abrir espaço para cogitar reformas. Isso tudo acontecia talvez a um ritmo um tanto lento para o temperamento impaciente de Lutz.

Pretendi chamar a atenção, principalmente, para os ajustes da agenda dos feminismos às circunstâncias dos sistemas políticos nos quais os grupos de mulheres atuavam. Ainda que fossem ambos presidencialistas, os sistemas políticos norte-americano e brasileiro guardavam fortes diferenças, que devem ser levadas em conta quando examinamos as estratégias de ativistas como Lutz. Portanto, sem uma investigação detalhada das variáveis que compõem cada experiência social onde os grupos feministas vicejavam, não superaremos a etapa de mitificação das lideranças passadas do feminismo (assim mesmo, no singular), o que confina a historiografia das mulheres no Brasil à permanente rememoração dos mesmos lugares-comuns. Perdem-se, assim, importantes chaves de compreensão sobre as possibilidades históricas da ação política de ativistas do movimento social.

\section{Referências}

ANDRADE, Geraldo E. Carmen Portinho. Rio de Janeiro: Ed. UERJ, 1999.

ARQUIVO DA CÂMARA DOS DEPUTADOS. Manifestações de grupos feministas em favor da nomeação de Bertha Lutz para a comissão de elaboração do Anteprojeto de Constituição. jul./ago. de 1932. Brasília, DF, 1933-1934. p. 1. [A 1933/34, 2:894, m:2, p: 1, J:3].

ARQUIVO HISTÓRICO DO ITAMARATY. Direitos da mulher. Rio de Janeiro, 1931-1939. [502.63, I.1237, m. 27. 558].

Congressos e Conferências Internacionais: assuntos gerais. Rio de Janeiro, 1931-1951. [100, I. 2064, 37.139] . VII Conferencia, a Interamericana, Montevideo, 1933. Direitos da

Mulher - propostas. Rio de Janeiro, 1933a. [962 VII, I. 1.417, m. 32.809].

. VII Conferencia Internacional Americana, Montevideo, 1933. Rio de Janeiro, 1933b. [962 VII, 9.279] 
ARQUIVO NACIONAL. Seção de Documentos Privados. Rio de Janeiro: Fundo FBPF. Sumário de atas, 1922-1946. (Instrumento de busca).

Seção de Documentos Privados. Fundo Bertha Lutz. Rio de Janeiro, 1912-1975. 247p. (Instrumento de busca). Bertha Lutz: correspondência. Rio de Janeiro, 12 fev. 1934, 1934. [AP 46, Cx 55, Pact 4, Doc 5; COR 1934-3.1 E 3.2].

Carta de Lutz a Carrie Chapman Catt. Rio de Janeiro, 26 mar. 1934. [AP 46, Cx 55, Pct 4, Doc. 16; COR 1934-4]. . Anotações para o projeto de livro sobre a história do feminismo, iniciadas em 8 de março de 1971. Registros sonoros de Bertha Lutz, fundo FBPF. [BR.AN.RIO.Q0.BLZ.APR. ELC.DSO.11].

BANDEIRA, L. A. Moniz. "A Guerra do Chaco." Revista Brasileira de Política Internacional, v. 41, n. 1, jan./jun. 1998.

BECKER, Susan D. The Origins of the Equal Rights Amendment. American Feminism Between the Wars. Westport/London: Greenwood Press, 1981.

BOLT, Christine. Sisterhood Questioned? Race, Class and Internationalism in the American and British Women's Movements, c. 1880-1970s. London/New York: Routledge, 2004.

BRASIL. Ministério das Relações Exteriores. Relatório da Delegação do Brasil à Conferência Interamericana sobre Problemas da Guerra e da Paz. Rio de Janeiro: Imprensa Nacional, 1945.

CHAVES, Wanderson da Silva. O Brasil e a recriação da questão racial no pós-guerra: um percurso através da história da Fundação Ford. 163 f. Tese (Doutorado em História) Faculdade de Filosofia, Letras e Ciências Humanas, Universidade de São Paulo, São Paulo, 2011.

GAMA, Almerinda Faria. Depoimento. Rio de Janeiro: FGV/ CPDOC, 1984.

LUTZ, Bertha. Os 13 Princípios Básicos. Sugestões ao anteprojeto da Constituição. Rio de Janeiro: Federação Brasileira pelo Progresso Feminino, 1933.

MARQUES, Teresa Cristina Novaes. "Bertha Lutz." In: SCHUMAHER, S.; BRASIL, E. Dicionário Mulheres do Brasil. 2 ed. Rio de Janeiro: Jorge Zahar, 2001 a.

“Verbete 'FBPF'." In: SCHUMAHER, S.; BRASIL, E. Dicionário Mulheres do Brasil. 2. ed. Rio de Janeiro: Jorge Zahar, $2001 b$.

"Worlds of Women. The Making of an International Women's Movement." Revista Ártemis, v. 14, ago./dez. 2012.

MARQUES, Teresa Cristina de Novaes; MELO, Hildete Pereira de. "Os direitos civis das mulheres casadas no Brasil entre 
1916 e 1962. Ou como são feitas as leis." Florianópolis: Estudos feministas, v. 16, n. 2, 440, maio/ago. 2008.

MEIRELES, Cecília. "O Trabalho Feminino no Brasil." O Observador Econômico e Financeiro, n. 42, Ano IV, jul. 1939.

NAZARIO, Diva Nolf. Voto feminino e feminismo. Um ano de feminismo entre nós. São Paulo: [s.n.], 1923.

RUPP, Leila J. Worlds of Women. The Making of an International Women's Movement. Princeton: Princeton University Press, 1997.

SOIHET, Rachel. O feminismo tático de Bertha Lutz. Florianópolis: Editora Mulheres; Santa Cruz do Sul: Edunisc, 2006.

VALOBRA, Adriana María. Del hogar a las urnas. Recorridos de la ciudadanía política feminina Argentina, 19461955. Rosário: Prohistoria Ediciones, 2010.

WHITE, Deborah Gray. Too Heavy a Load. Black Women in Defense of Themselves, 1894-1994. New York: W.W. Norton \& Company, 1999.

WOOD, Bryce. The Making of the Good Neighbor Policy. New York: Norton Library, 1967.

[Recebido em 28 de março de 2012, reapresentado em 24 de março de 2013 e aceito para publicação em 18 de abril]

Between the Equalitarism and Women's Rights Reformation:Bertha Lutz at Montevideo Interamerican Conference, 1933

Abstract: The Interamerican Conference of Montevideo, that took place in November 1933, is the starting point of a long and consistent cooperation between Bertha Lutz and Brazilian diplomacy. During the same conference, a radical faction of North American feminism - the National Party of Women - obtained a temporary political victory. Lutz opposed the NWP due to her own convictions and personal bounds to other feminist groups.

This essay examines the reasons why diplomatic milieu adhered to the defense of women's rights. The debate of Montevideo also enhances the understanding of Bertha Lutz's political thought, as well as opens new historiography perspectives to the question of the political cultures of feminisms.

Key Words: Political Culture of Feminisms; Bertha Lutz; Equal Rights.

944 Estudos Feministas, Florianópolis, 21(3): 927-944, setembro-dezembro/2013 